\title{
Pembinaan dan Penilaian Instrumen Ujian Aptitud Kemasukan ke Institut Pengajian Tinggi Malaysia
}

\author{
Development and Evaluation of an Aptitute Test for Bachelor Degree Entrance in \\ Malaysian Institution of Higher Learning \\ Zulkifley Mohamed ${ }^{1}$, Othman Lebar ${ }^{2} \&$ Shahrizal Shamsuddin ${ }^{3}$ \\ 1,3Jabatan Matematik, Fakulti Sains dan Matematik \\ ${ }^{2}$ Jabatan Pengajian Pendidikan, Fakulti Pembangunan Manusia \\ Universiti Pendidikan Sultan Idris, Tanjong Malim, Perak, 35900, Malaysia \\ e-mail: zulkifley@fsmt.upsi.edu.my
}

\begin{abstract}
Abstrak
Artikel ini membincangkan pembinaan dan penilaian instrumen Ujian Aptitud (UA) yang digunakan bagi kemasukan ke program Sarjana Muda, Institut Pengajian Tinggi (IPT) Malaysia. Pendekatan kuantitatif dengan reka bentuk pembangunan penyelidikan yang melibatkan kaedah tinjauan digunakan dalam kajian ini. Pembinaan instrumen UA adalah berdasarkan model Benson dan Clark. Instrumen UA yang dibina terdiri daripada atribut taakulan matematik yang dikenal pasti melalui penelitian karya. Instrumen UA dinilai oleh enam orang pakar dalam bidang matematik, statistik, bahasa dan pentaksiran pendidikan dan diuji ke atas sampel kajian. Kesahan soalan UA dinilai berdasarkan Nisbah Kesahan Kandungan (NKK) manakala pekali Kuder Richardson (KR20) digunakan bagi menilai kebolehpercayaan. Sampel yang menjadi subjek kajian dipilih menggunakan kaedah pensamplean berstrata terdiri daripada 270 pelajar Sijil Tinggi Persekolahan Malaysia (STPM), Matrikulasi dan Diploma yang memasuki salah sebuah IPT tempatan. Kajian yang dilakukan berjaya membina instrumen UA yang mengandungi 15 soalan algebra, 13 soalan analisis data dan kebarangkalian, 13 soalan nombor dan operasi, dan 16 soalan geometri dan pengukuran. Dapatan kajian menunjukkan bahawa 91 peratus soalan memenuhi kesahan kandungan dengan NKK melebihi .67. Ujian kebolehpercayaan terhadap soalan yang dibina mendapat nilai KR20 pada julat .80 dan .93 , manakala nilai $K R 20$ bagi keseluruhan soalan adalah .87. Kesimpulannya, kajian yang dijalankan berjaya membina dan menilai instrumen UA bagi kemasukan ke IPT. Implikasinya, instrumen UA yang dibina sesuai digunakan sebagai salah satu kaedah penilaian kemasukan ke IPT dan boleh diperluas penggunaannya kepada agensi-agensi yang menawarkan pembiayaan pengajian dalam memilih set pelajar yang terbaik.
\end{abstract}

Kata kunci Pembinaan, penilaian, instrumen, Ujian Aptitud (UA), atribut taakulan matematik

\begin{abstract}
This article discusses the development and evaluation of an Aptitude Test (AT) instrument used for bachelor degree programs entrance in Malaysian Institution of Higher Learnings (IHLs). The quantitative approach with research and development designs involving the survey method was utilized in this study. The development of the AT instrument was
\end{abstract}


based on Benson and Clark model. The developed AT instrument consists of mathematics reasoning attributes that were determined by reviewing of the literature. The AT instrument was evaluated by six experts in the field of mathematics, statistics, language, and education assessment and was tested on the studied sample. The validity of AT questions was evaluated based on the Content Validity Ratio (CVR) while Kuder Richardson (KR20) coefficient was used to evaluate its reliability. The sample that was chosen as a study subject was selected using stratified sampling consisted of 270 Malaysia Higher Certificate of Education (HSE), Matriculation and Diploma students enrolled in one of local IHLs. The study successfully developed the AT instrument which consists of 15 algebra questions, 13 probability and data analysis questions, 13 number and operation questions, and 16 measurement and geometry questions. The findings revealed that 91 percent of the questions fulfilled the content validity requirement with the CVR exceeded .67. The reliability of the developed questions showed the $K R 20$ value is in the range between .80 and .93 , while the $K R 20$ value of the overall questions was .87. In conclusion, the study has successfully developed and evaluated the AT instrument for IHLs entrance. The implication, AT instrument that was developed is suitable to be used as one of the methods to assess IHLs entrance and its usage can be extended to select the best set of students for other agencies that offered study funds.

Keywords Development, evaluation, Aptitute Test (AT) instrument, mathematics reasoning attributes

\section{PENGENALAN}

Kementerian Pengajian Tinggi Malaysia membuka peluang seluas-luasnya kepada pelajar untuk melanjutkan pelajaran. Pelajar yang berjaya menamatkan pengajian diharap dapat memberi sumbangan yang baik kepada negara di samping mendapat kemahiran dan pengetahuan bagi memenuhi keperluan kerjaya. Justeru, kesinambungan pendidikan berkualiti perlu diteruskan agar pelajar-pelajar yang bakal dididik mendapat pendidikan yang benar-benar berkualiti daripada tenaga pengajar yang berkualiti yang dihasilkan oleh sesebuah universiti.

Bagi memastikan graduan yang berkualiti dapat dihasilkan oleh IPT, salah satu faktor yang perlu diberi perhatian adalah kelayakan masuk. Pelajar yang memiliki kelayakan masuk ke IPT yang bersesuaian kebiasaannya tidak menghadapi masalah dalam meneruskan pengajian di IPT. Justeru, bagi menyaring kemasukan pelajar ke IPT, di samping menggunakan kaedah yang sedia ada, satu kaedah perlu digunakan sebagai pelengkap dalam memilih satu set pelajar yang mampu mengharungi kehidupan di IPT. Kajian telah dilakukan bagi membina dan menilai instrumen yang digunakan bagi menyaring kemasukan pelajar ke IPT yang dikenali sebagai instrumen Ujian Aptitud (UA) dengan mengambil kira atribut yang bersesuaian sebagai pelengkap untuk membolehkan pelajar berjaya di IPT dan menghasilkan pelajar yang berkualiti.

\section{PENYATAAN MASALAH}

Amalan pengambilan pelajar ke IPT di Malaysia adalah berdasarkan pencapaian dalam peperiksaan STPM, Matrikulasi atau Diploma. Ketiga-tiga jenis peperiksaan ini merupakan peperiksaan piawai yang telah digunakan sekian lama. Disebabkan persaingan memasuki ke IPT begitu mencabar, pihak IPT hanya memiilih pelajar yang berada di kedudukan teratas 
dari segi pencapaian di peringkat STPM, Matrikulasi atau Diploma. Bagi IPT yang hanya mengambil bilangan pelajar yang terhad, IPT tersebut akan menggunakan kaedah masingmasing umpamanya temuduga bagi menyaring pelajar yang terbaik untuk ditempatkan di IPT masing-masing. Menurut Kong et al. (2003), Kuncel dan Hezlett (2007), Martha (2009), dan Jeotee (2012), kelayakan masuk ke IPT mempengaruhi pencapaian akademik semasa berada di IPT. Salah satu cara bagi memilih set pelajar yang bersesuaian untuk memasuki ke IPT adalah dengan menilai kemahiran taakulan yang dimiliki pelajar sebagai pelengkap kepada kaedah pemilihan yang sedia ada. Kemahiran taakulan merupakan alat bagi membuat keputusan secara sistematik dan abstrak (Fischhoff et al., 1999). Kemahiran taakulan boleh dinilai melalui UA, Salkind dan Rasmussen (2007) mentakrifkan UA sebagai satu set perlakuan yang dikaitkan dengan kebolehan memperoleh pengetahuan dan kemahiran. UA berperanan mengukur keseluruhan prestasi pelajar yang merangkumi kebolehan mental (Hashmi et al., 2012, Raza \& Shah, 2011). Terdapat banyak UA yang diaplikasi diserata dunia, antaranya adalah skala kecerdasan Stanford-Binet (Thorndike et al., 1986), skala kecerdasan untuk kanak-kanak Weschler (Weschler, 2004), ujian kognitif WoodcockJohnson (WJ-R) (Schrank et al., 2014), ujian kecerdasan tanpa lisan sejagat (McCallum \& Bracken, 2005), Kaufman Adolescent and Adult Intelligence Test (KAIT) (Kaufman \& Kaufman, 2004), sistem penilaian kognitif(Naglieri \& Otero, 2012), Scholastic Assessment Test (SAT) dan American College Test (ACT). Walau bagaimanapun di Malaysia, masih kurang atau tiada penggunaan UA yang bersesuaian bagi memilih pelajar memasuki IPT sebagai pelengkap kepada kaedah yang sedia ada. Kertas ini membincangkan pembinaan dan penilaian instrumen UA yang berfokus kepada UA matematik bersesuaian dengan kepentingan memilih pelajar dalam bidang Sains, Teknologi, Kejuruteraan dan Matematik (STEM). Instrumen ini bukan sahaja boleh digunakan oleh IPT, malah instrumen ini boleh diperluas penggunaannya kepada agensi-agensi yang menawarkan pembiayaan pengajian dalam memilih set pelajar yang terbaik.

\section{OBJEKTIF KAJIAN}

Kajian yang dilakukan bertujuan membina instrumen UA bagi memilih pelajar yang memohon ke IPT. Objektif utama kajian ini adalah mengenal pasti atribut taakulan matematik, membina dan menguji kesahan dan kebolehpercayaan instrumen UA.

\section{METODOLOGI}

Pendekatan kuantitatif dengan reka bentuk pembangunan penyelidikan yang melibatkan kajian tinjauan digunakan dalam kajian ini. Pembinaan instrumen UA adalah berdasarkan model Benson dan Clark (1982). Model pembinaan instrumen Benson dan Clark melibatkan empat fasa iaitu perancangan, pembinaan instrumen UA, penilaian instrumen UA, dan kesahan instrumen UA berdasarkan bukti dapatan.

\section{Fasa 1: Perancangan}

Fasa perancangan adalah bagi mengenal pasti kumpulan sasar penggunaan instrumen, kerangka dan konsep, dan domain konstruk yang dibina. Kumpulan sasar kajian ini adalah 
pelajar STPM, Matrikulasi dan Diploma. yang akan memasuki IPT. Kajian yang dijalankan menggunakan kerangka dan konsep SAT yang menguji empat komponen utama matematik, iaitu algebra, analisis data dan kebarangkalian, nombor dan operasi, dan geometri dan pengukuran. Menurut Graves (2002) terdapat kesamaan antara SAT dan ujian aptitud bagi mengukur kecerdasan. Instrumen UA yang dibina adalah berdasarkan saranan yang dikemukakan oleh Rudner dan Schafer (2002), Kaplan dan Saccuzzo (2009), dan Sternberg (2007), iaitu bagi menilai sesuatu ujian, standard yang harus diberi perhatian ialah liputan ujian dan penggunaan, sampel yang sesuai untuk ujian kesahan, kesahan jangkaan, kesahan kandungan, kesahan konstruk, kebolehpercayaan, pentadbiran ujian, laporan ujian, dan ujian kepincang item. Atribut dan faktor kecerdasan yang dikenal pasti melalui penelitian karya diuji ke atas sampel kajian.

\section{Fasa 2: Pembinaan Instrumen}

Pembinaan instrumen UA dilakukan oleh pakar matematik, statistik, bahasa, dan pentaksiran pendidikan dari Universiti Pendidikan Sultan Idris (UPSI) dengan mengambil kira aras taksonomi soalan dan penjajaran konstruktif. Dalam pembentukan soalan sesuatu instrumen, beberapa taksonomi boleh dijadikan panduan. Dalam kajian ini, pembentukan soalan adalah berdasarkan taksonomi Bloom (Anderson et al. 2001, Forehand, 2005) bagi mengukur kemahiran intelek dan berfikir. Sebelum kajian sebenar dijalankan, satu kajian rintis telah dijalankan. Tujuan utama kajian rintis ini dijalankan ialah untuk memurnikan instrumen UA dan seterusnya menilai kefahaman responden terhadap pengukuran kandungan kajian yang dapat menjawab soalan-soalan kajian.

\section{Fasa3: Penilaian Kesahan dan Kebolehpercayaan Instrumen}

Dapatan sesuatu kajian amat bergantung kepada instrumen kajian yang digunakan. Kesahan dan kebolehpercayaan instrumen yang bakal digunakan perlu dipastikan terlebih dahulu oleh penyelidik agar dapatan kajian tidak dipertikai. Kesahan sesuatu instrumen kajian merujuk kepada sejauh mana instrumen tersebut mengukur apa yang sepatutnya diukur (Drost, 2011). Terdapat tiga jenis kesahan yang utama, iaitu kesahan muka, kesahan kandungan, dan kesahan kriteria (Kaplan \& Saccuzzo, 2009). Dalam kajian ini, kesahan kandungan instrumen dengan kaedah kritikan luaran digunakan. Kesahan sesuatu instrumen dinilai berdasarkan Nisbah Kesahan Kandungan (NKK) (Lawshe, 1975) yang mengambil skor yang diperolehi daripada penilaian pakar. Nilai NKK di antara .30 dan .40 dikira tinggi dalam menentukan kesahan sesuatu instrumen kajian (Kaplan \& Saccuzzo, 2009). Menyentuh tentang bilangan pakar yang diperlukan bagi menilai instrumen kajian, 6 hingga 9 orang pakar adalah memadai dalam membuat penilaian terhadap item-item yang dipilih atau dibina oleh penyelidik (Mohd. Majib, 2004).

Salah satu kriteria yang membolehkan instrumen kajian diterima adalah kebolehpercayaan. Kebolehpercayaan dirujuk sebagai darjah ketekalan atau kestabilan sesuatu instrumen kajian apabila digunakan berulang kali terhadap subjek kajian yang sama (Hogan, 2013). Bagi membolehkan item-item instrumen dalam kajian diterima, nilai pekali kebolehpercayaan yang dicadangkan adalah melebihi 7 (Kaplan \& Saccuzzo, 2009). Terdapat beberapa cara untuk menganggar kebolehpercayaan sesuatu ujian. Empat 
asas umum yang paling kerap digunakan adalah uji-uji semula, bentuk alternatif, ketekalan dalaman, dan penilaian antara penguji (Coaley, 2014). Dalam kajian ini, kaedah ketekalan dalaman berdasarkan pekali KR20 digunakan bagi menilai kebolehpercayaan soalan-soalan UA bersesuaian dengan data berbentuk dikotomi.

\section{Fasa 4: Kesahan Instrumen berdasarkan Bukti Dapatan}

Bagi membina instrumen UA, penyelidik membuat penelitian karya secara mendalam. Pemboleh ubah yang menjadi tumpuan kajian disenaraikan sebanyak mungkin dan dioleh menjadi soalan UA oleh pakar dalam bidang matematik, statistik dan pentaksiran pendidikan. Analisis penjajaran konstruktif dan spesifikasi ujian dilakukan terhadap instrumen UA yang dibina. Item yang kurang sesuai digugurkan dan seterusnya digantikan dengan item baharu yang lebih sesuai. Kesahan dan kebolehpercyaan instrumen UA disahkan melalui dapatan kajian secara emperikal.

\section{SAMPEL KAJIAN}

Persampelan rawak berstrata digunakan dalam memilih sampel kajian. Subjek kajian distratakan mengikut program pengajian yang diikuti, iaitu pengajian STPM, Matrikulasi dan Diploma. Subjek yang menjadi sampel kajian terdiri daripada 270 pelajar STPM, Matrikulasi dan Diploma yang dipilih secara rawak yang telah ditawarkan memasuki di salah sebuah IPT di Malaysia.

\section{DAPATAN KAJIAN}

\section{Kandungan Instrumen UA}

Instrumen UA yang dibangunkan mengandungi empat bahagian iaitu algebra, analisis data dan kebarangkalian, nombor dan operasi, dan geometri dan pengukuran. Soalan-soalan yang terkandung dalam instrumen UA dibentuk berdasarkan taksonomi Bloom. Tahap kemahiran yang diuji pula adalah berdasarkan tahap Sijil Pelajaran Malaysia (SPM), STPM, Matrikulasi dan Diploma. Instrumen UA dibangunkan oleh pakar matematik, statistik, bahasa, dan pentaksiran pendidikan Universiti Pendidikan Sultan Idris (UPSI) berdasarkan konsep SAT. Perincian kandungan instrumen UA yang dibangunkan adalah seperti pada Jadual 1.

Jadual 1 Definisi Operasi Kandungan Instrumen UA

\begin{tabular}{ll}
\hline Kandungan & Definisi Operasi \\
\hline Algebra & Kandungan algebra meliputi operasi asas menggunakan nombor \\
& bulat, perpuluhan, pecahan, integer, nilai tempatan, punca kuasa dua \\
& dan anggaran, konsep eksponen, tata tanda saintifik, faktor, nisbah \\
& dan peratusan. Persamaan linear, nilai mutlak, susunan nombor \\
& berdasarkan nilai, ciri-ciri eksponen dan punca kuasa dua, penilaian \\
& persamaan algebra melalui penggantian, menggunakan pemboleh ubah \\
& untuk mengungkap fungsi hubungan, memahami operasi algebra, dan \\
& penyelesaian persamaan kuadratik dengan pemfaktoran. \\
\hline
\end{tabular}


Jadual 1 Sambungan...

\begin{tabular}{ll}
\hline Kandungan & Definisi Operasi \\
\hline Analisis Data dan & Kandungan analisis data dan kebarangkalian meliputi teknik asas \\
penghitungan dan kebarangkalian, pemungutan data, persembahan \\
data dan penghuraian, asas statistik deskriptif, penelitian pelbagai \\
cara pemungutan dan persembahan data, menganalisis dan mentaksir \\
variasi dalam data, dan anggaran populasi.
\end{tabular}

Terdapat 57 soalan aneka pilihan yang dibangunkan dalam instrumen UA. Soalansoalan dibentuk dalam tiga set dan setiap set mengandungi 19 soalan. Penjajaran soalan mengikut kandungan soalan ditunjukkan pada Jadual 2.

Jadual 2 Kandungan Keseluruhan Soalan UA

\begin{tabular}{ccccc}
\hline & \multicolumn{4}{c}{ Kandungan Soalan } \\
\cline { 2 - 5 } & Algebra & $\begin{array}{c}\text { Analisis Data da } \\
\text { Kebarangkalian }\end{array}$ & $\begin{array}{c}\text { Nombor dan } \\
\text { Operasi }\end{array}$ & $\begin{array}{c}\text { Geometri dan } \\
\text { Pengukuran }\end{array}$ \\
\hline Bilangan soalan & 15 & 13 & 13 & 16 \\
\hline Peratus & 26.31 & 22.81 & 22.81 & 28.07 \\
\hline
\end{tabular}

Ujian statistik khi kuasa dua menunjukkan bahawa bilangan soalan UA yang dibangunkan adalah seimbang $\left(X^{2}(3, n=57)=.474, p=.925\right)$ dengan keseluruhan terdapat 15 (26.3\%) soalan algebra, $13(22.8 \%)$ soalan analisis data dan kebarangkalian, $13(22.8 \%)$ soalan nombor dan operasi, dan 16 (28.1\%) soalan geometri dan pengukuran. 


\section{Jadual Spesifikasi Ujian UA}

Pembinaan instrumen UAmengambil kira aras taksonomi dan berdasarkan Jadual Spesifikasi Ujian (JSU). Taburan soalan mengikut aras taksonomi dipaparkan pada Jadual 3.

Jadual 3 Jadual Spesifikasi Ujian UA

\begin{tabular}{|c|c|c|c|c|c|}
\hline \multirow[b]{2}{*}{ Kandungan } & \multicolumn{4}{|c|}{ Aras Taksonomi } & \multirow[b]{2}{*}{$\begin{array}{l}\text { Jumlah } \\
\text { Soalan }\end{array}$} \\
\hline & Kefahaman & Aplikasi & Analisis & Sintesis & \\
\hline Algebra & 3 & 5 & 7 & & 15 \\
\hline $\begin{array}{l}\text { Analisis Data dan } \\
\text { Kebarangkalian }\end{array}$ & & 7 & 4 & 2 & 13 \\
\hline Nombor dan Operasi & 2 & 6 & 4 & 1 & 13 \\
\hline Geometri dan Pengukuran & & 7 & 9 & & 16 \\
\hline Jumlah Soalan & 5 & 25 & 24 & 3 & \\
\hline Peratus & 8.77 & 43.86 & 42.11 & 5.26 & \\
\hline
\end{tabular}

Soalan-soalan dalam instrumen UA hanya melibatkan aras kefahaman, aplikasi, analisis dan sintesis sahaja tanpa melibatkan soalan aras penilaian bersesuaian dengan tahap pengajian pelajar. Berdasarkan aras taksonomi, didapati bahawa soalan-soalan yang dibangunkan memiliki aras yang berbeza dengan soalan lebih tertumpu kepada aras aplikasi dan analisis, manakala nisbah yang rendah adalah bagi soalan-soalan aras kefahaman dan sintesis $\left(X^{2}(3, n=57)=29.67, p<.05\right)$.

\section{Kesahan Instrumen}

Kajian yang dilakukan mendapati 52 soalan UA mendapat NKK melebihi .50. Selebihannya 5 soalan mendapat nilai NKK kurang daripada .50. Soalan-soalan yang mendapat nilai NKK kurang daripada .50 melambangkan kesahan yang diragui dan diganti dengan soalan baharu. Dalam kajian ini lima soalan digugurkan dan diganti dengan soalan baharu. Nilai NKK bagi keseluruhan 57 soalan dipaparkan pada Jadual 4.

Jadual 4 Penilaian Panel Pakar dan NKK $\left[\left(2 n_{a} / N\right)-1\right]$

\begin{tabular}{cccccccc}
\hline \multicolumn{7}{c}{ Panel Pakar } \\
\hline Soalan & A & B & C & D & E & F & $\begin{array}{c}\text { Nilai } \\
\text { NKK }\end{array}$ \\
\hline 1 & 1 & 1 & 1 & 1 & 1 & 1 & 1.00 \\
2 & 1 & 1 & 1 & 1 & 1 & 1 & 1.00 \\
3 & 1 & 1 & 1 & 1 & 1 & 1 & 1.00 \\
4 & 1 & 1 & 1 & 1 & 1 & 1 & 1.00 \\
5 & 0 & 1 & 1 & 1 & 1 & 1 & 0.67 \\
6 & 1 & 0 & 0 & 0 & 1 & 0 & -0.33 \\
7 & 1 & 1 & 1 & 1 & 1 & 1 & 1.00 \\
8 & 1 & 1 & 1 & 1 & 1 & 1 & 1.00 \\
9 & 1 & 1 & 1 & 1 & 1 & 1 & 1.00 \\
10 & 1 & 1 & 1 & 1 & 1 & 1 & 1.00 \\
11 & 1 & 1 & 1 & 1 & 1 & 1 & 1.00 \\
\hline
\end{tabular}


Jadual 4 Sambungan...

\begin{tabular}{|c|c|c|c|c|c|c|c|}
\hline \multicolumn{8}{|c|}{ Panel Pakar } \\
\hline Soalan & A & B & $\mathrm{C}$ & $\mathrm{D}$ & $\mathrm{E}$ & $\mathrm{F}$ & $\begin{array}{l}\text { Nilai } \\
\text { NKK }\end{array}$ \\
\hline 12 & 1 & 1 & 1 & 1 & 1 & 1 & 1.00 \\
\hline 13 & 1 & 1 & 1 & 1 & 1 & 1 & 1.00 \\
\hline 14 & 1 & 1 & 1 & 1 & 1 & 1 & 1.00 \\
\hline 15 & 1 & 1 & 1 & 1 & 1 & 1 & 1.00 \\
\hline 16 & 0 & 1 & 0 & 0 & 0 & 0 & -0.67 \\
\hline 17 & 1 & 1 & 1 & 1 & 1 & 1 & 1.00 \\
\hline 18 & 1 & 1 & 1 & 1 & 1 & 1 & 1.00 \\
\hline 19 & 1 & 1 & 1 & 1 & 1 & 1 & 1.00 \\
\hline 20 & 1 & 1 & 1 & 1 & 1 & 1 & 1.00 \\
\hline 21 & 1 & 1 & 1 & 1 & 1 & 1 & 1.00 \\
\hline 22 & 1 & 1 & 1 & 1 & 1 & 1 & 1.00 \\
\hline 23 & 1 & 1 & 1 & 1 & 1 & 1 & 1.00 \\
\hline 24 & 1 & 1 & 1 & 1 & 1 & 1 & 1.00 \\
\hline 25 & 1 & 1 & 1 & 1 & 1 & 1 & 1.00 \\
\hline 26 & 1 & 1 & 1 & 1 & 1 & 1 & 1.00 \\
\hline 27 & 0 & 0 & 0 & 0 & 0 & 0 & -1.00 \\
\hline 28 & 1 & 1 & 1 & 1 & 1 & 1 & 1.00 \\
\hline 29 & 1 & 1 & 1 & 1 & 1 & 1 & 1.00 \\
\hline 30 & 1 & 1 & 1 & 1 & 1 & 1 & 1.00 \\
\hline 31 & 1 & 1 & 1 & 1 & 1 & 1 & 1.00 \\
\hline 32 & 1 & 1 & 1 & 1 & 1 & 1 & 1.00 \\
\hline 33 & 1 & 1 & 1 & 1 & 1 & 1 & 1.00 \\
\hline 34 & 1 & 1 & 1 & 1 & 1 & 1 & 1.00 \\
\hline 35 & 1 & 1 & 1 & 1 & 1 & 1 & 1.00 \\
\hline 36 & 1 & 1 & 1 & 1 & 1 & 1 & 1.00 \\
\hline 37 & 1 & 1 & 1 & 1 & 1 & 1 & 1.00 \\
\hline 38 & 1 & 1 & 1 & 1 & 1 & 1 & 1.00 \\
\hline 39 & 0 & 0 & 1 & 0 & 0 & 1 & -0.33 \\
\hline 40 & 1 & 1 & 1 & 1 & 1 & 1 & 1.00 \\
\hline 41 & 1 & 1 & 1 & 1 & 1 & 1 & 1.00 \\
\hline 42 & 1 & 1 & 1 & 1 & 1 & 1 & 1.00 \\
\hline 43 & 1 & 1 & 1 & 1 & 1 & 1 & 1.00 \\
\hline 44 & 1 & 1 & 1 & 1 & 1 & 1 & 1.00 \\
\hline 45 & 1 & 1 & 1 & 1 & 1 & 1 & 1.00 \\
\hline 46 & 1 & 1 & 1 & 1 & 1 & 1 & 1.00 \\
\hline 47 & 1 & 1 & 1 & 1 & 1 & 1 & 1.00 \\
\hline 48 & 1 & 1 & 1 & 1 & 1 & 1 & 1.00 \\
\hline 49 & 1 & 1 & 1 & 1 & 1 & 1 & 1.00 \\
\hline 50 & 1 & 1 & 1 & 1 & 1 & 1 & 1.00 \\
\hline 51 & 0 & 0 & 0 & 0 & 0 & 0 & -1.00 \\
\hline 52 & 1 & 1 & 1 & 1 & 1 & 1 & 1.00 \\
\hline 53 & 1 & 1 & 1 & 1 & 1 & 1 & 1.00 \\
\hline 54 & 1 & 1 & 1 & 1 & 1 & 1 & 1.00 \\
\hline 55 & 1 & 1 & 1 & 1 & 1 & 1 & 1.00 \\
\hline 56 & 1 & 1 & 1 & 1 & 1 & 1 & 1.00 \\
\hline 57 & 1 & 1 & 1 & 1 & 1 & 1 & 1.00 \\
\hline
\end{tabular}

Catatan: 1 melambangkan persetujuan dengan soalan yang dibina.

0 melambangkan tidak bersetuju dengan soalan yang dibina. 


\section{Kebolehpercayaan Instrumen}

Nilai yang diperoleh daripada pekali KR20 dalam menilai kebolehpercayaan soalan-soalan UA adalah di antara .80 dan .93 bagi setiap kandungan soalan. Manakala bagi keseluruhan soalan UA, nilai pekali KR20 adalah .87 seperti yang ditunjukkan pada Jadual 5.

Jadual 5 Nilai KR20 Mengikut Kandungan Soalan

\begin{tabular}{lc}
\hline Kandungan & Nilai $K R 20$ \\
\hline Algebra & .80 \\
Analisis Data dan Kebarangkalian & .82 \\
Nombor dan Operasi & .93 \\
Geometri dan Pengukuran & .81 \\
\hline Keseluruhan & .87 \\
\hline
\end{tabular}

Dalam membincangkan nilai pekali KR20, Kaplan dan Saccuzzo (2009) mencadangkan bahawa nilai dalam lingkungan .70 dan .80 adalah mencukupi bagi melambangkan kebolehpercayaan soalan ujian. Dapatan kajian mendapati bahawa soalan-soalan UA yang dibina mencapai tahap kebolehpercayaan yang baik. Empat contoh soalan UA yang dibina beserta penerangan bagi setiap soalan dipaparkan pada Jadual 6 .

Jadual 6 Contoh Soalan UA

\begin{tabular}{|l|l|l|}
\hline 2. If $m^{2}=17$, than the value for $(m+1)(m-1)$ is & $\begin{array}{l}\text { Algebra: } \\
\text { Penyelesaian } \\
\text { persamaan kuadratik } \\
\text { dengan pemfaktoran. }\end{array}$ \\
(A) $\sqrt{17-1}$ & \\
(B) $\sqrt{17+1}$ \\
(C) 16 \\
(D) 18 \\
The below table shows the number of badminton tournament played \\
by Hanif from the year 2005 to 2010. In what year he played more \\
than $50 \%$ from the previous year? \\
\begin{tabular}{|l|c|c|c|c|} 
kebarangkalian: Data \\
dan penghuraian.
\end{tabular} \\
$\begin{array}{l}\text { Number of } \\
\text { Tournament }\end{array}$ \\
(A) 2006 \\
(B) 2007 \\
(C) 2008 \\
(D) 2009
\end{tabular}


Jadual 6 Sambungan...

\begin{tabular}{|c|c|}
\hline Soalan & Penerangan \\
\hline $\begin{array}{l}\text { 12. If } \boldsymbol{M} \text { is increase by } 10 \% \text { and } \boldsymbol{N} \text { is decrease by } 10 \% \text {, if the formation } \\
\text { of both values are the same, what is ratio of } \boldsymbol{M} \text { to } \boldsymbol{N} \text { ? } \\
\begin{array}{llll}\text { (A) } \frac{9}{11} & \text { (B) } \frac{9}{10} & \text { (C) } 1 & \text { (D) } \frac{10}{9}\end{array}\end{array}$ & $\begin{array}{l}\text { Nombor dan operasi: } \\
\text { Maksud dan model } \\
\text { operasi asas pecahan. }\end{array}$ \\
\hline $\begin{array}{l}\text { 12. } 40^{\circ} \\
\text { What is the value of } \boldsymbol{y} \text { in the above diagram? } \\
\text { (A) } 17.5 \\
\text { (B) } 20 \\
\text { (C) } 28 \\
\text { (D) } 36\end{array}$ & $\begin{array}{l}\text { Geometri dan } \\
\text { pengukuran: } \\
\text { Meneroka bagaimana } \\
\text { konsep matematik } \\
\text { menerangkan } \\
\text { pengukuran secara } \\
\text { tidak langsung. }\end{array}$ \\
\hline
\end{tabular}

\section{KESIMPULAN DAN CADANGAN}

Kajian yang dilakukan berjaya membina instrumen UA bagi kemasukan ke IPT. Instrumen UA yang dihasilkan adalah bagi menguji penaakulan matematik. Instrumen UA yang dihasilkan ditabir selama 60 minit bagi setiap sesi ujian. Instrumen UA dibina berdasarkan kerangka dan konsep yang disarankan oleh Rudner dan Schafer (2002), Kaplan dan Saccuzzo (2009) dan Sternberg (2007). Pembinaan soalan-soalan adalah berdasarkan taksonomi Bloom. Bagi memastikan instrumen UA yang dibangunkan memenuhi standard yang ditetapkan, kajian yang dilakukan menggunakan penjajaran konstruktif dan JSU serta melalui beberapa kriteria penilaian. Kriteria-kriteria yang dimaksudkan adalah kesahan kandungan dan ujian kebolehpercayaan. Ujian kesahan dilakukan oleh enam orang pakar dalam bidang matematik, statistik, bahasa dan pentaksiran pendidikan UPSI. Manakala ujian kebolehpercayaan dijalankan terhadap sampel yang terdiri daripada 270 pelajar STPM, Matrikulasi dan Diploma yang memasuki salah buat IPT tempatan.

Soalan-soalan bagi instrumen UA terdiri daripada domain kefahaman, aplikasi, analisis dan sentisis. Oleh kerana soalan-soalan yang dibangun adalah bagi menguji pelajar peringkat pra universiti, kesimbangan aras soalan adalah penting. Kebanyakan soalan tertumpu pada aras aplikasi dan analisis, manakala sebahagiannya sahaja pada aras kefahaman dan sintesis. Ini bersesuaian dengan matlamat kajian dalam penentuan peratus aras taksonomi soalan yang dikaitkan dengan tahap kognitif pelajar pra universiti. Soalansoalan yang dibina terdiri daripada 9 peratus soalan kefahaman, 44 peratus soalan aplikasi, 42 peratus soalan analisis dan 5 peratus soalan sintesis. Bertepatan dengan matlamat kajian yang memerlukan kesimbangan kandungan soalan yang dibina, instrumen UA terdiri daripada 26 peratus soalan algebra, 23 peratus soalan analisis data dan kebarangkalian, 23 peratus soalan nombor dan operasi, dan 28 peratus soalan geometri dan pengukuran. 
Menyentuh tentang kesahan kandungan, kebanyakan soalan memenuhi kriteria kesahan kandungan. Walau bagaimanapun terdapat lima soalan yang ditolak oleh pakar penilai dan diganti dengan soalan baharu. Soalan baharu yang dibina telah dinilai semula oleh pakar penilai dan akhirnya semua pakar penilai bersetuju dengan soalan yang dibangunkan dalam kontek kesahan kandungan. Kebolehpercayaan soalan-soalan yang dibina melepasi standard yang ditetapkan dan secara keseluruhan kesemua soalan mencatatkan nilai $K R 20$ melebihi .70.

Kajian yang dilakukan mencadangkan agar UA digunakan bagi pemilihan pelajar ke IPT dan boleh diperluas penggunaannya kepada agensi-agensi yang menyumbang pembiayaan pengajian di IPT dalam memilih set pelajar yang terbaik. Walau bagaimanapun beberapa kajian yang melibatkan instrumen UA iaitu hubungan korelasi di antara UA dan gred yang diperolehi bagi setiap mata pelajaran di peringkat STPM, matrikulasi dan Diploma perlu dilakukan. UA tidak seharusnya mengambil alih kaedah pemilihan ke IPT yang sedia. Ia hanya sebagai kriteria tambahan bagi pemilihan agar dapat memantapkan kaedah pemilihan ke IPT.

\section{PENGHARGAAN}

Penghargaan kepada Pusat Penyelidikan dan Inovasi, Universiti Pendikan Sultan Idris di atas keberhasilan artikel ini melalui pemberian geran penyelidikan universiti 2011-0157107-01.

\section{RUJUKAN}

Anderson, L.W., Krathwohl, D.R., Airasian, P.W., Cruikshank, K.A., Mayer, R.E., Pintrich, P.R., Raths, J., \& Wittrock, M.C., (Pnyt.) (2001). A Taxonomy for learning, teaching, and assessing. New York, NY: Addison Wesley Longman Inc.

Benson, J., \& Clark, F. (1982). A guide for instrument development and validation. The American Journal of Occupational Therapy, 36, 789-800. Diakses pada 8 Nov. 2016, dpd: http://dx.doi. org/10.5014/ajot.36.12.789

Benson, J., \& Clark, F. (1982). A guide for instrument development and validation. American Journal of Occupational Therapy, 36(12), 789-800.

Coaley, K. (2014). An introduction to psychological assessment and psychometrics. London: Sage Publication.

Drost, E. A. (2011). Validity and reliability in social science research. Education Research and perspectives, 38(1), 105.

Fischhoff, B., Crowell, N.A., \& Kipke, M. (1999). Adolescent decision making: Implications for prevention programs. Washington, DC: National Academy Press.

Forehand, M. (2005). Bloom's taxonomy: Original and revised. Dalam M. Orey (Pnyt.). Emerging perspectives on learning, teaching and technology. Diakses pada 8 Nov. 2016, dpd:http://www. textbookequity.org/oct/Textbooks/Orey_Emergin_Perspectives_Learning.pdf

Graves, J.L. (2002). The misuse of life history theory: J.P. Rushton and the pseudoscience of racial hierarchy. Dalam J.M. Fish (pnyt). Race and intelligence: Separating science from myth. Nahwah, NJ: Lawrence Erlbaum Associates.

Hashmi, M. A., Zeeshan, A., Saleem, M., \& Akbar, R. A. (2012). Development and validation of an aptitude test for secondary school mathematics students. Bulletin of Education and Research, 34(1). 
Hogan, T. P. (2013). Psychological testing: A practical introduction. Wiley Global Education.

Jeotee, K. (2012). Reasoning skills, problem solving ability and academic ability: implications for study programme and career choice in the context of higher education in Thailand (Doctoral dissertation, Durham University).

Kaplan, R. M., \& Saccuzzo, D. P. (2017). Psychological testing: Principles, applications, and issues. Nelson Education.

Kaplan, R. M., \& Saccuzzo, D. P. (2009). Psychological testing: Principles, applications, and issues. (7 $7^{\text {th }}$ Edition). Belmont, CA: Wadsworth.

Kaufman, A. S., \& Kaufman, N. L. (2004). Kaufman brief intelligence test. John Wiley \& Sons, Inc.

Kong, Q. P., Wong, N. Y., \& Lam, C. C. (2003). Student engagement in mathematics: Development of instrument and validation of construct. Mathematics Education Research Journal, 15(1), 4-21.

Kuncel, N.R., \& Hezlett, S.A. (2007). Standardized tests predict graduate students' success. Science, $315,1080-1081$.

Lawshe, C. H. (1975). A quantitative approach to content validity. Personnel psychology, 28(4), 563-575.

Martha, K. (2009). Factors affecting academic performance of undergraduate students at Uganda Christian University. Unpub. Master of Arts in Educational Management Dissertation, Makerere University, Uganda.

McCallum, R.S., \& Bracken, B.A. (2005). The universal nonverbal intelligence test, a multidimensional measure of intelligence. In D.P., Flanagan, \& P.L., Harrison. Contemporary intellectual assessment: Theories, tests, and issues ( $3^{\text {rd }}$ Edition). New York, NY: Guilford Press. 425-440.

Mohd. Majid Konting (2004). Kaedah penyelidikan pendidikan. Kuala Lumpur: Dewan Bahasa dan Pustaka.

Naglieri, J.A., \& Otero, T.M. (2012). The cognitive assessment system: From theory to practice. Dalam D.P. Flanagan, \& P.L. Harrison. Contemporary intellectual assessment: Theories, tests, and issues ( $3^{\text {rd }}$ Edition). New York, NY: Guilford Press. 376-399.

Raza, M. A., \& Shah, A. F. (2011). Impact of favourite subject towards the scientific aptitude of the students at elementary level. Pakistan Journal of Social Sciences (PJSS), 31(1), 135-143.

Rudner, L.M., \& Schafer. W.D. (2002). What teachers need to know about assessment. Washington, DC: National Education Association.

Salkind, N.J., \& Rasmussen, K. (2007). Encyclopaedia of measurement and statistics. London: Sage Publications.

Schrank, F.A., McGrew, K.S., \& Mather, N. (2014). Woodcock-Johnson IV tests of cognitive abilities examiner's manual, standard and extended batteries. Itasca, IL: Riverside.

Mather, N. (2001). Woodcock-Johnson III Tests of Cognitive Abilities examiner's manual. Riverside Pub..

Sternberg, R.J. (2007). Wisdom, intelligence, and creativity synthesized. New York, NY: Cambridge University Press.

Thorndike, R.L., Hagen, E.P., \& Sattler, J.M. (1986). Stanford-Binet intelligence scale (4 ${ }^{\text {th }}$ Edition). Chicago, IL: Riverside.

Wechsler, D. (2004). The Wechsler intelligence scale for children (4 ${ }^{\text {th }}$ Edition). London: Pearson Assessment. 